\title{
Library Book Selection Decisions and Selectors' Effectiveness: Differences among Librarians, Faculty, and Students
}

\author{
William H. Walters, John Gormley, Amy E. Handfield, \\ Bernadette M. López-Fitzsimmons, Susanne Markgren, \\ Laurin Paradise, and Sarah E. Sheehan
}

This study examines the book selections of 22 Manhattan College librarians, faculty, and students who were asked to make yes or no decisions for 287 books reviewed in CHOICE. It focuses on four research questions. First, What characteristics are associated with selected and nonselected books? Although there is only modest agreement among selectors, yes decisions are associated with favorable reviews, appropriateness for lower-division undergraduates, reasonable price, publication by a university press, and the absence of caveats in the review. The results suggest that selectors are willing to relax certain selection criteria if others are exceeded, that selectors' generally favorable attitudes toward multidisciplinary works do not extend to all such books, and that titles in areas unfamiliar to the selector are less likely to be chosen. Second, What are the key differences among the book selections of librarians, faculty, and undergraduates? Although there are minor differences among all three groups, the main finding is that students' selections are relatively unpredictable and less closely linked to particular book and review characteristics. Third, What are the key differences among the book selections of specialists (faculty and librarians) in the natural sciences, the social sciences, and the humanities? Although the three subject groups are similar in their yes/no decisions and in the characteristics of the books they choose, most selectors demonstrate a strong tendency to favor books in their own subject areas. Finally, What individual characteristics are associated with effectiveness as a book selector? Librarians and faculty are equally effective, overall. Faculty have an advantage among selectors without book selection experience, but the positive impact of experience is greater for librarians than for faculty. In contrast, students are relatively ineffective selectors, and their choices are not closely related to those of other students, faculty, or librarians.

\footnotetext{
* All the authors are at Manhattan College (Riverdale, New York), where William H. Walters is Executive Director of the Library, John Gormley is Reference and Instruction Librarian, Amy E. Handfield is Assistant Director of the Library for Access Services, Bernadette M. López-Fitzsimmons is Associate Librarian, Susanne Markgren is Assistant Director of the Library for Technical Services, Laurin Paradise is Reference and Instruction Librarian, and Sarah E. Sheehan is Assistant Director of the Library for Reference and Instruction; e-mail: william.walters@ manhattan.edu. We are grateful for the assistance of Ashley Cross, Jennifer C. Edwards, Lance S. Evans, Thomas Ferguson, Daniel Genet, Kajol Ghotra, Timothy G. Gress, Jalah Jarvis, Marisa Lerer, Maria Maust-Mohl, Maggie Murray, Helene R. Tyler, and Christopher Urban-Klein. (C2020 William H. Walters, John Gormley, Amy E. Handfield, Bernadette M. López-Fitzsimmons, Susanne Markgren, Laurin Paradise, and Sarah E. Sheehan, Attribution-NonCommercial (https://creativecommons.org/licenses/by-nc/4.0/) CC BY-NC.
} 


\section{Introduction}

Academic libraries acquire books through a wide range of mechanisms, including approval plans, publisher- or vendor-supplied e-book collections, and patron-driven acquisition (PDA) programs that allow patrons to choose books from a preselected set. Nonetheless, title-by-title selection remains the gold standard because it allows for the closest match between patrons' needs and the resources that might meet those needs. ${ }^{1}$ After all, it is individual books or chapters - not collections or databases - that students and faculty evaluate, select, and use in their academic work.

Within the title-by-title selection framework, librarians and faculty are often jointly responsible for book selection. The two groups may select books independently, or faculty may submit their recommendations to liaison librarians or subject bibliographers for approval. Although quite a few authors have investigated the relative effectiveness of various selection paths-approval plans vs. PDA, for instance ${ }^{2}-$ no recent studies have evaluated the characteristics of the books selected individually by librarians, faculty, and students. Likewise, no studies have investigated the distinctive characteristics of each group's selections or the individual attributes that make some selectors more effective than others.

We examined the book selections of seven Manhattan College librarians, eight full-time faculty, and seven undergraduates who were asked to serve as selectors - to make yes or no decisions for 287 of the books reviewed by CHOICE in November 2017. ${ }^{3}$ Each individual adopted the role of a generalist selector and worked from a common set of book selection guidelines. We also evaluated study participants' comments with regard to 48 particular books - those for which there were clear discrepancies between the reviewers' ratings and the selectors' decisions, or for which one group's evaluations were substantially different from another's.

Although the study is largely exploratory, it focuses on four research questions:

1. What characteristics are associated with selected and nonselected books (that is to say, yes and no selection decisions)?

2. What are the key differences among the book selections of librarians, faculty, and undergraduates?

3. What are the key differences among the book selections of specialists (faculty and librarians) in the natural sciences, the social sciences, and the humanities?

4. What individual characteristics are associated with effectiveness as a book selector? In particular, how do librarian/faculty/student status, professional experience, and book selection experience influence effectiveness - the extent to which the individual selector's choices match those of the group as a whole?

Our results have the potential to improve book selection by exploring the influence of various book and selector characteristics on selection decisions, by assessing whether those decisions are congruent with the college's book selection guidelines, and by drawing attention to the unique perspectives of librarians, faculty, and students, and to the ways in which their selection decisions differ. Although our findings are based on data for one particular institution, the methods can be adopted by a wide range of colleges and universities. Finally, a better understanding of selectors' behavior may eventually contribute to a conceptual model of book selection that accounts for the interaction of book characteristics, selectors' characteristics, and institutional context (curriculum, students, faculty, institutional priorities, and available resources). 


\section{Previous Research}

To our knowledge, no empirical studies have evaluated the characteristics of effective book selectors - the personal attributes and experiences that lead to success in book selection. However, a number of papers have examined the characteristics of selected and nonselected books, compared the book selections of librarians and faculty, and evaluated the selections of undergraduates. Previous research informs our analyses-our choice of methods, for instance - and allows us to interpret our results in light of earlier findings.

\section{Characteristics of Selected and Nonselected Books}

Interviewing 20 librarian selectors at 19 US universities in 2017, Zhang identified three primary considerations in e-book selection: price, content, and projected use, in that order. ${ }^{4}$ In a similar study, Shoki found that the book characteristics most often considered by academic librarians in Nigeria include currency, publisher's reputation, and author's reputation. ${ }^{5}$ Although Shoki did not explicitly account for institutional characteristics - the match between a book's subject and the university's curriculum, for instance-his results suggest that readability and, by extension, appropriateness for undergraduates is not a major factor in selectors' decisions.

\section{Librarians and Faculty as Book Selectors}

Departmental faculty had sole responsibility for book selection at most college and university libraries until the 1960s, when shared responsibility became the norm. By 1967, more than 90 percent of academic libraries relied on librarians for at least some selections. ${ }^{6}$ Although librarians now bear ultimate responsibility for book selection at most universities, the faculty and librarian roles vary substantially among institutions and even among academic departments. ${ }^{7}$ Librarians and faculty may select books independently or collaboratively, with or without an established division of responsibility.

Along with the shift toward librarians as selectors, another change has occurred. In 1967, most librarian selectors (bibliographers) were based in stand-alone collection development or acquisitions units. These days, however, book selection is more likely to be assigned to liaison librarians with primary duties in areas such as reference and instruction. As Sorgenfrei and Hooper-Lane have noted, factors such as time constraints, limited subject knowledge, and lack of administrative support may keep reference and instruction librarians from reaching their potential as book selectors. ${ }^{8}$ Relatively few librarians are collection development specialists, and many of those with book selection responsibilities have little or no collection development training. ${ }^{9}$

Departmental faculty have several advantages as selectors: subject expertise, knowledge of top authors and cutting-edge work, awareness of instructors' expectations of students, and firsthand experience with departmental curricula, goals, and priorities. Faculty with tenure may resist any form of oversight, however, which can be a problem when the library's collection development goals are organizationally rather than individually determined. The strengths of librarian selectors include professional knowledge, awareness of students' reading and study habits, a strong commitment to undergraduates who have not yet selected a major, understanding of the library collection as a whole, overall knowledge of the curriculum (in many cases), and a concern for technical and licensing issues that the faculty may not appreciate. ${ }^{10}$

Attempts to evaluate the effectiveness of librarians and faculty as book selectors have focused almost exclusively on library circulation. This is unfortunate, since use represents 
just one aspect of utility for teaching and research. ${ }^{11}$ Moreover, nearly all the relevant studies were undertaken before the 1990s, when both selection processes and faculty/librarian roles were different. Four of the seven studies we identified, including the two most recent ones, show modestly higher circulation for librarian-selected books than for faculty-selected books. ${ }^{12}$ For instance, Connell reported an average of 2.3 circulations during a two-year period for librarian-selected books and 1.9 circulations for faculty-selected books. Just one study found a contrary relationship; the books selected by the business faculty of Emory University had a higher three-year circulation rate (75\%) than those selected by the business librarians (67\%). ${ }^{13}$ Adopting a different approach, Vidor and Futas found that librarians were more likely than faculty to choose the books that were subsequently reviewed in five key publications. Librarians selected 71 percent of the reviewed books; faculty, 63 percent. ${ }^{14}$

Just a few authors have investigated the ways in which librarians and faculty differ in their approaches to book selection. In 1969, Evans asked librarians and faculty at four universities to rate the importance of various considerations in their book selection decisions. ${ }^{15} \mathrm{He}$ found that librarians and faculty are similar in their book selection priorities. Likewise, a 2010 study at Purdue University led to much the same conclusion; 85 percent of the PDA books selected by faculty and graduate students were titles that the subject librarians would have ordered for the collection, and all but 1 percent met the more relaxed standard of appropriate for the collection. ${ }^{16}$ When asked to choose the factors that influence their book selection decisions, faculty at Keane University overwhelmingly selected good for students (51\%), good for teaching $(27 \%)$, and good for faculty $(11 \%)$, criteria that presumably reflect both subject scope and intended audience. ${ }^{17}$ Perhaps surprisingly, respondents were unlikely to choose the four response options that correspond to specific book characteristics: author's reputation (3\%), publisher's reputation (3\%), "contents interesting" $(3 \%)$, and price $(1 \%)$.

Jenkins examined the use of book reviews as selection tools at the College of Mount St. Joseph, reporting that 88 percent of librarians but just 39 percent of faculty used book reviews when selecting books. ${ }^{18}$ The faculty percentage rose to 60 percent, however, when respondents from the Department of Religion were excluded. Finally, Chu interviewed 36 faculty and 12 subject librarians to explore their perspectives on book selection. ${ }^{19}$ Several consistent findings emerged.

1. Both subject librarians and faculty tend to focus on the needs of their own departments and students; neither group is strongly committed to the strength of the collection as a whole. Despite their emphasis on departmental needs, faculty feel that the book collection is weakest in interdisciplinary areas.

2. Lack of time is the main constraint on the faculty's participation in book selection. Communication is also a problem - not between faculty and librarians, but within each academic department.

3. Faculty are not prompt about selecting new books, and some are more likely to fill in gaps through retrospective selection than to select new books in anticipation of need. Faculty feel that they would be more effective as selectors if librarians would provide them with more extensive guidance with regard to selection tools (for instance, CHOICE reviews), collection priorities, and evaluation methods.

\section{Undergraduate Students as Book Selectors}

Several papers have discussed librarians' advantages - and undergraduates' disadvantages as book selectors. ${ }^{20}$ Although students may have greater subject knowledge, especially in areas 
such as accounting and engineering, librarians are likely to be more knowledgeable about research strategies, information resources, cultural and historical contexts, academic norms, and institutional characteristics. Librarians have successfully completed the academic tasks that many students struggle with.

The differences between librarians and undergraduates can be seen in their book selections. In 2011, Shen and associates demonstrated that relatively few of the books selected by students at Sam Houston State University would have been acquired by the subject librarians. ${ }^{21}$ Only 30 percent of the patrons' selections were included in the librarians' lists of items they would purchase if unlimited funds were available to them. Patrons were also more than twice as likely to select nonscholarly titles. In 2013, Waller reached a similar conclusion based on the books chosen by undergraduates at Saint Anselm College. ${ }^{22}$ More recent data suggest that there may be important disciplinary differences in students' effectiveness as selectors. Researchers at the University of Nebraska found that, in the natural and social sciences, the books selected by librarians had substantially higher citation rates than those selected by undergraduates. In the humanities, however, the books chosen by undergraduates had higher citation rates than those selected by librarians or faculty. ${ }^{23}$

No studies have directly examined the methods or criteria used by undergraduates when selecting books for academic library collections. Students' use of library resources may shed light on their perspectives and priorities, however. For instance, interviews with undergraduates at Gustavus Adolphus College suggest that the most important factors, other than subject relevance, are familiarity (with the search interface, for instance), reputation/credibility, convenience, format/type (book or article, print or online), and external influence (guidance from professors and peers). ${ }^{24}$ Accuracy of content and accessibility (in terms of reading level and required background knowledge) were almost never mentioned by Gustavus Adolphus students.

Likewise, Stieve and Schoen selected 11 research topics, identified two scholarly books on each topic, and asked undergraduates at Niagara University to choose one book from each pair. ${ }^{25}$ Their results show that a key consideration for students is how readily the information in the book can be read, evaluated, and adopted for their own purposes. For instance, students who were asked to compare the perspectives of two philosophers might appreciate a book in which each chapter corresponds to a single philosopher and the same topics (section headings) appear within each chapter. Students prefer books with high-quality indexes and detailed tables of contents that allow them to find and use relevant information easily. Other important selection criteria include year of publication, size of print, and size of the book (not page count, but portability). The author's reputation, the publisher's reputation, the number of pages, and the physical condition of the book are not among the factors generally considered by students.

\section{Research Design}

This study provides insight into the selection decisions made by librarians, faculty, and undergraduates at Manhattan College (MC), a private university with 3,500 undergraduates and 500 graduate students. Twenty-two study participants were asked to examine 287 of the November 2017 CHOICE reviews - all those without a Reference designation - and to select the books they would order for the MC library collection. ${ }^{26}$ Each CHOICE review, authored by a faculty member or academic librarian, includes written commentary, an overall rating of the 
book, and a readership statement specifying the intended audience. The possible ratings are 0 stars (not recommended), 1 star (optional), 2 stars (recommended), 3 stars (highly recommended), and 4 stars (essential). ${ }^{27}$ Because the readership statements tend to use similar language, all but one of the 287 books could be readily placed into one of three readership categories: 1 (lower-division students and above), 2 (upper-division students and above), or 3 (graduate students, faculty, and professionals). ${ }^{28}$

\section{The Selectors (Study Participants)}

The 22 selectors include seven librarians, eight full-time faculty, and seven undergraduates, each identified by a code. The first letter of each code indicates the status of the study participant: librarian (L), faculty (F), or student (S). This is followed by the participant's subject field: physical sciences (Phys), life sciences (Life), social sciences (Soc), education (Ed), languages (Lang), philosophy (Phil), history (Hist), or fine arts (Fine), with Gen used to designate librarians without prior selection experience in a particular subject area.

- Librarians: LLife, LSoc, LLang, LGen1, LGen2, LGen3, and LGen4

- Faculty: FPhys, FLife, FSoc, FEd, FLang, FPhil, FHist, and FFine

- Students: SPhys, SLife, SSoc1, SSoc2, SLangSoc (double major), SLang, and SPhil

For analytical purposes, the $50 \mathrm{CHOICE}$ subject fields were initially collapsed into nine categories - the eight listed above, plus Business. However, most of the analyses presented here make use of three broader categories: NAT (natural sciences), SOC (social sciences), and HUM (humanities).

None of the selectors had access to the November CHOICE reviews prior to the selection exercise, and none of the books were ordered before the exercise was completed. This ensured that the selectors' decisions were not influenced by knowledge of which books were actually acquired by the library. The seven librarian selectors were required to participate in the exercise as part of their collection development training. ${ }^{29}$ Although each librarian had a dual role as study participant and coauthor, all but the Social Sciences librarian (LSoc) were treated strictly as study participants until all the selections and comments had been submitted. (LSoc selected books before the other selectors had done so.) The faculty and student selectors were recruited by the librarians based on their subject expertise and their willingness to participate.

\section{The Book Selection Process}

Each study participant evaluated books in every subject area, adopting the role of a generalist selector and submitting a yes or no decision for each book (each review). Each was asked to work in accordance with the librarians' book selection guidelines (see appendix) ${ }^{30}$ and to assume that the faculty in the academic departments - those not participating in the selection exercise - would also be allowed to independently choose books for their research. The study participants therefore worked from the assumption that titles not appropriate for student use would not need to be chosen as part of the selection exercise. The selectors were free to seek out additional information or not, as they chose, and were instructed to assume that the library would pay the lowest print price (softcover) for each selected book.

No limit was set on the number of books that could be ordered or the total cost of the books, although selectors were reminded that "any money spent on these books is money not spent on other library books, academic journals, online databases, etc. For that reason, you'll want to select only the books that seem genuinely useful to students and faculty here 
at Manhattan College." The selectors were informed that LSoc had chosen 132 of the 287 books (46\%) but that they "should feel free to select more, or fewer, based on your own assessments." 31 Some sets of yes/no decisions were received after just a few days, in November 2017, while others were not received until April 2018. To evaluate the influence of selectors' characteristics on their book selection decisions, we also compiled information on the extent (in years) of each individual's book selection experience, professional experience as a faculty member or librarian, and experience at Manhattan College.

\section{Statistical and Qualitative Methods}

Our analyses make use of simple descriptive and inferential statistics - frequency tables, crosstabulations, correlations, and ordinary least-squares (OLS) regression. ${ }^{32}$ Because the sample of selectors is neither random nor representative, significance tests are not appropriate in this context. The constraints of the sample also limit our ability to generalize to any group other than the participants themselves.

Once the quantitative results were compiled, 56 books of special interest were identified: 12 with clear discrepancies between the reviewers' ratings and the selectors' decisions; 25 that a particular selector group (librarians, faculty, or students) was especially likely or unlikely to select; and 31 that a particular subject group (NAT, SOC, or HUM) was especially likely or unlikely to select. Some books appeared in more than one category. For 48 of the 56 books, chosen at random, the selectors were asked to describe the primary considerations in their selection decisions. Specifically, each selector was asked to comment on 6 to 12 books. If a book was chosen by a number of selectors despite an unfavorable review, we solicited the comments of at least one person who had selected the book and at least one who had not. Likewise, if a book was selected by several students but by none of the librarians, we solicited the comments of at least one student and at least one librarian. We received 161 written comments from 15 selectors - seven librarians, four faculty, and four students. Those 15 respondents commented on every one of the 48 books, and on more general issues that arose as they reflected on the selection process.

This study also evaluates selectors' effectiveness. Our definition of effectiveness is discussed more fully later, but it is based on the idea that effective selection is that which represents the collective interests of the three main stakeholder groups: librarians, faculty, and students. Consequently, effective selectors are those whose decisions most closely match the choices of the 22 selectors combined. Each selector's effectiveness was calculated as the point-biserial correlation between his or her selection decisions (coded 1 for yes, 0 for no) and the overall selection rates for each of the 287 books.

\section{Results}

\section{Book Selection Rates and the Role of Subject Knowledge}

For the set of 22 selectors, the mean selection rate is 46 percent. That is, a typical selector chose 46 percent of the November 2017 CHOICE books for the MC library collection. The selection rate is not uniform across disciplines, however; it ranges from 35 percent in the fine arts to 56 percent in education. The high selection rate for education may reflect broad interest in educational topics among academics and students, or the fact that relatively few education books are reviewed in CHOICE. (We assume that, if only the best books are reviewed, a higher proportion will be chosen.) The low selection rate in the fine arts can be attributed at least 
partly to the Manhattan College context, since the arts are not well represented in the $\mathrm{MC}$ curriculum or in the selectors' subject backgrounds.

Several selectors noted that the CHOICE reviews in the fine arts seemed to include a high proportion of very specialized books. That impression, in turn, may reflect the selectors' limited knowledge of the field. As one librarian pointed out, the default decision is no. A yes decision therefore requires that the selector make a case for the book by drawing on his or her knowledge. This suggests a general collection development principle-that greater subject knowledge leads to higher selection rates. In contrast, more limited knowledge leads to fewer selections.

Overall, the selectors were seldom in close agreement about particular titles. Nearly half the books were chosen by at least 30 percent of the selectors but by fewer than 70 percent, and the selectors' decisions are only weakly related to each other (average phi $=0.25$ ). There were no unanimous yes decisions, although two books - The Idea of the Muslim World and Set in Stone: America's Embrace of the Ten Commandments - were selected by all but one of the study participants. ${ }^{33}$

\begin{tabular}{|c|c|c|c|}
\hline \multicolumn{4}{|c|}{$\begin{array}{c}\text { TABLE } 1 \\
\text { Descriptive Data for Books, by Percentage of }\end{array}$} \\
\hline & $\begin{array}{l}\text { Average for } \\
\text { All Books, } \\
\text { Selected and } \\
\text { Nonselected }\end{array}$ & $\begin{array}{c}\text { Average for } \\
\text { Books Selected } \\
\text { by } 0 \%-19 \% \text { of } \\
\text { Selectors }\end{array}$ & $\begin{array}{c}\text { Average for } \\
\text { Books Selected } \\
\text { by } 70 \%-99 \% \text { of } \\
\text { Selectors }\end{array}$ \\
\hline Average reviewer rating & 2.5 & 2.0 & 3.2 \\
\hline Percent with 4-star ratings (essential) & 8 & 0 & 30 \\
\hline Percent with 3-star ratings (highly recommended) & 34 & 12 & 59 \\
\hline Percent with 2-star ratings (recommended) & 55 & 74 & 11 \\
\hline Percent with 1-star ratings (optional) & 3 & 12 & 0 \\
\hline Percent with 0 -star ratings (not recommended) & 0 & 2 & 0 \\
\hline Percent with caveats/reservations & 3 & 9 & 0 \\
\hline Average readership level & 1.7 & 2.2 & 1.3 \\
\hline Percent in readership category 1 (lower-div.) & 47 & 25 & 67 \\
\hline Percent in readership category 2 (upper-div.) & 35 & 32 & 33 \\
\hline Percent in readership category 3 (grad./prof.) & 17 & 42 & 0 \\
\hline Percent from university presses & 65 & 49 & 79 \\
\hline Median price & 39.95 & 59.95 & 34.95 \\
\hline Average price & 54.38 & 70.44 & 42.43 \\
\hline Percent with high price & 30 & 53 & 11 \\
\hline Percent with low price & 27 & 21 & 36 \\
\hline Median pages & 280 & 287 & 296 \\
\hline Average pages & 304 & 295 & 341 \\
\hline Percent long books & 30 & 33 & 39 \\
\hline Percent short books & 30 & 35 & 20 \\
\hline \multicolumn{4}{|c|}{$\begin{array}{l}\text { High price is } \$ 59.95 \text { (70th percentile) or more. Low price is } \$ 29.99 \text { (30th percentile) or less. Long books are } \\
324 \text { pages ( } 70 \text { th percentile) or more. Short books are } 239 \text { pages ( } 30 \text { th percentile) or fewer. }\end{array}$} \\
\hline
\end{tabular}




\section{Characteristics of Selected and Nonselected Books}

Descriptive statistics. Several book characteristics are closely associated with positive or negative selection decisions. As we might expect, there is a strong correlation between the reviewer's rating and the selection rate-the percentage of selectors who selected the book $($ rho $=0.60)$. For instance, 95 percent of the books with reviewer ratings of 4 had selection rates of 50 percent or higher. In contrast, none of the books with ratings of 1 or 0 had selection rates of 50 percent or higher.

Table 1 shows how reviewer rating, readership category, price, and other characteristics vary with selection rate. The books chosen by at least 70 percent of the selectors tend to have high reviewer ratings and few caveats or reservations in the text of the review. They are generally appropriate for lower-division undergraduates, published by university presses, and available at a reasonable price. In contrast, the books selected by fewer than 20 percent of the selectors tend to have the opposite characteristics.

Readership category and publisher type (university press or commercial publisher) are especially good predictors of selection status. Of the books selected by at least 70 percent of the selectors, 67 percent are in readership category 1 (lower-division) and 79 percent are published by university presses. While some academics might assume that university presses tend to publish more specialized books, there is almost no correlation between readership category and university press status $($ rho $=0.11)$.

\begin{tabular}{|c|c|c|c|c|c|c|c|c|}
\hline \multicolumn{9}{|c|}{$\begin{array}{l}\text { TABLE } 2 \\
\text { Book Characteristics That Influence Selection Decisions, for All Selectors and for Each of } \\
\text { Three Selector Groups-OLS Regression Results }\end{array}$} \\
\hline & \multicolumn{2}{|c|}{ All Selectors } & \multicolumn{2}{|c|}{ Librarians } & \multicolumn{2}{|c|}{ Faculty } & \multicolumn{2}{|c|}{ Students } \\
\hline & B & SE & $B$ & SE & $B$ & SE & $B$ & $\mathrm{SE}$ \\
\hline Rating (stars) & 18.5 & 1.5 & 17.2 & 2.1 & 21.8 & 1.8 & 15.9 & 1.9 \\
\hline Caveats in review & -13.7 & 6.3 & -16.8 & 8.6 & -20.1 & 7.1 & -3.1 & 7.8 \\
\hline Readership category 2 & -6.0 & 2.3 & -6.0 & 3.2 & -5.6 & 2.7 & -6.3 & 2.9 \\
\hline Readership category 3 & -20.6 & 3.1 & -22.7 & 4.2 & -29.0 & 3.5 & -9.0 & 3.9 \\
\hline University press & 4.8 & 2.3 & 6.5 & 3.1 & 5.9 & 2.6 & 1.9 & 2.8 \\
\hline Social science & 4.2 & 2.6 & 4.7 & 3.5 & 2.6 & 2.9 & 5.7 & 3.2 \\
\hline Natural science & 2.6 & 2.7 & -2.5 & 3.7 & 3.9 & 3.1 & 6.3 & 3.4 \\
\hline High price & -6.0 & 2.6 & -9.6 & 3.5 & -5.0 & 2.9 & -3.6 & 3.2 \\
\hline Low price & 4.3 & 2.7 & 3.8 & 3.7 & 3.3 & 3.0 & 5.9 & 3.3 \\
\hline Long book & -1.8 & 2.5 & -0.4 & 3.5 & 1.3 & 2.9 & -6.7 & 3.2 \\
\hline Short book & -5.1 & 2.4 & -9.2 & 3.4 & -1.3 & 2.8 & -5.4 & 3.1 \\
\hline Constant & 4.8 & 5.2 & 7.5 & 7.2 & -1.0 & 5.9 & 8.6 & 6.5 \\
\hline Adjusted $\mathrm{R}^{2}$ & 0.52 & & 0.40 & & 0.55 & & 0.28 & \\
\hline SE of estimate & 16.9 & & 23.3 & & 19.2 & & 21.2 & \\
\hline \multicolumn{9}{|c|}{$\begin{array}{l}\text { The dependent variable is the selection rate (\%) for each book, across the set of all selectors and for each } \\
\text { of the three selector groups; } \mathrm{n}=287 \text { books. } \\
\text { Readership category } 1 \text { and humanities are the reference categories. } \\
\text { High price, low price, long book, and short book are defined in table } 1 . \\
B \text { and SE are not standardized. }\end{array}$} \\
\hline
\end{tabular}


Selectors' avoidance of high-priced books is also notable. While low-priced books have only a slight advantage in their chance of being selected, high-priced books are at a clear disadvantage. Of the books chosen by at least 70 percent of the selectors, only 11 percent have prices of $\$ 59.95$ or more.

Regression results. The leftmost columns of table 2 (all selectors) further demonstrate how selection rates are influenced by various book characteristics. (The other columns, which present separate results for librarians, faculty, and students, will be discussed later.)

The table 2 regression results are distinct from the table 1 data in two respects. First, each regression coefficient $(B)$ shows the independent effect of a particular characteristic or status - the impact of the variable if all other characteristics were held constant. Price and university-press status are related, for instance, but table 2 disentangles that relationship and shows the separate impact of each. Second, the regression coefficients reveal the magnitude of each effect. Each $B$ coefficient shows the change in selection rate, in percentage points, that is associated with the characteristic. For instance, a one-star increase in the reviewer's rating can be expected to increase the percentage of selectors who choose the book by 18.5 percentage points. Likewise, a switch from readership category 1 (the default category, lower-division) to category 2 (upper-division) can be expected to reduce the selection rate by 6.0 percentage points. ${ }^{34}$ (Readership category 1 is not shown in the table, since it is the reference category; its effect is simply the absence of the effects associated with readership category 2 and readership category 3. Likewise, humanities is the reference category with regard to academic discipline.)

Overall, the most effective predictors of selection rate are reviewer's rating, readership category, high price, and the presence or absence of caveats in the review. The adjusted $\mathrm{R}^{2}$ value, 0.52 , indicates that the 11 variables, taken together, explain roughly half of the variation in selection rates. The remaining variation can be attributed to (a) the systematic effects of variables not represented in table 2 and (b) apparently random differences in selection rates that are specific to each individual book.

Selectors' comments. Fifteen respondents provided comments on their selections, describing their reasons for selecting, or not selecting, particular titles of interest. A content analysis of their comments led to the identification of nearly two dozen reasons for their yes and no decisions (see table 3).

As the table shows, one attribute - "relevance to particular programs, courses, or instructors at Manhattan College" - was mentioned often, in both positive and negative terms. That is, relevance was mentioned 36 times as a reason for selection while nonrelevance was mentioned 30 times as a reason for nonselection. Two respondents pointed out that high relevance was enough to overcome a negative review. FFine noted that a book with a one-star review would nonetheless be potentially useful for one of her courses, while SLife felt that A Curriculum of Fear: Homeland Security in U.S. Public Schools would be of such broad interest that students should have an opportunity to judge for themselves whether the zero-star rating was warranted. ${ }^{35}$

Although relevance was expressed in both positive and negative terms-relevant or not relevant - the other characteristics mentioned by respondents can be readily categorized as either reasons for selection (positive) or reasons for nonselection (negative). For instance, "too specialized" was mentioned as a negative attribute 42 times while "not too specialized" was mentioned only twice as a positive attribute (see table 3). The table also reveals that 17 of the 22 reasons for selection or nonselection can be incorporated into five broader themes: Scope of the collection, Intended audience, Quality of the book, Price, and Publisher. 


\begin{tabular}{|c|c|c|}
\hline $\begin{array}{c}\text { TABLE } 3 \\
\text { Reasons for Selection or Nonselection Mentioned by } 15 \text { Respondents- } \\
\text { Each Reason Was Mentioned }\end{array}$ & -Number & of Times \\
\hline & Positive & Negative \\
\hline Scope of the Collection & & \\
\hline Relevant [or not relevant] to particular programs, courses, or instructors at MC & 36 & 30 \\
\hline $\begin{array}{l}\text { Useful in multiple disciplines [as a negative attribute: author attempted to cover/ } \\
\text { integrate multiple disciplines but was not successful] }\end{array}$ & 21 & 5 \\
\hline Covers a topic that is "hot" or especially important at the moment & 16 & 0 \\
\hline $\begin{array}{l}\text { Especially relevant to the college itself or to the NYC area due to topic, authorship, } \\
\text { and other factors }\end{array}$ & 3 & 0 \\
\hline Topic is underrepresented within the MC library collection & 1 & 0 \\
\hline Not a genre or format that we normally collect (such as workbooks) & 0 & 2 \\
\hline Book chapters were previously published as articles & 0 & 1 \\
\hline Intended Audience & & \\
\hline $\begin{array}{l}\text { Too specialized; topic is so specific that the book is unlikely to be used [as a } \\
\text { positive attribute: broad topic is likely to appeal to many MC students] }\end{array}$ & 2 & 42 \\
\hline $\begin{array}{l}\text { Readership category is not appropriate for our students; more appropriate for } \\
\text { advanced researchers }\end{array}$ & 0 & 24 \\
\hline Popular; not a scholarly work & 0 & 5 \\
\hline Quality of the Book & & \\
\hline $\begin{array}{l}\text { Author's topic, perspective, or argument is original or innovative [as a negative } \\
\text { attribute: not original or innovative; would not add a distinctive element to our } \\
\text { current holdings] }\end{array}$ & 10 & 2 \\
\hline Author overstates his or her claims, or does not support them with evidence & 0 & 7 \\
\hline Reviewer's rating is low [as a positive attribute: reviewer's rating is high] & 3 & 5 \\
\hline Author seems biased in a way that limits the utility of the book & 0 & 2 \\
\hline $\begin{array}{l}\text { Text of the review suggests problems/caveats even though the reviewer's rating is } \\
\text { not low }\end{array}$ & 0 & 2 \\
\hline Price & & \\
\hline Price is too high [as a positive attribute: price is low] & 5 & 19 \\
\hline Publisher & & \\
\hline Publisher is not well regarded [as a positive attribute: publisher is well regarded] & 1 & 7 \\
\hline Other Reasons & & \\
\hline Includes primary historical source material & 7 & 0 \\
\hline Students may want to read the book for fun & 2 & 0 \\
\hline The review itself is unclear or poorly written; does not inspire a yes decision & 0 & 2 \\
\hline Selector questions the rating assigned by the reviewer & 4 & 1 \\
\hline Selector may have misunderstood something mentioned in the review & 2 & 0 \\
\hline
\end{tabular}


The first theme, Scope of the collection, incorporates seven specific criteria, most of which were viewed in positive terms. Although respondents generally favored books that might be useful in multiple disciplines, their comments also revealed a negative aspect of multidisciplinarity. In five separate remarks, selectors mentioned that attempts to cover multidisciplinary topics were not always successful. LLang described The Language of Plants: Science, Philosophy, Literature as "perhaps too interdisciplinary" while LGen2 felt that it was "vague and esoteric," with little connection to the work actually undertaken by students in the environmental studies program. ${ }^{36}$ Several selectors questioned the utility of books on scientific topics written by authors without scientific expertise.

The second theme, Intended audience, was mentioned almost entirely in negative terms. That is, selectors remarked not on the appropriateness of particular books, but on their inappropriateness for this particular audience. The single most common negative comment, "too specialized" - a reference to content rather than style of presentation-appeared 42 times. A related comment, "readership category is not appropriate," was used with reference to style of presentation-vocabulary, reading level, or mathematical sophistication, for instance.

The third theme, incorporating five specific points, deals with the Quality of the book, as expressed by the CHOICE reviewers or inferred by the selectors. Ten separate remarks praised particular books as especially original or innovative in terms of their topics, perspectives, or arguments. As table 3 reveals, there were also a number of negative comments in this category; most mentioned unfavorable reviews, insufficient evidence, or bias.

Price was mentioned 24 times, usually in negative terms. That is, high prices made selectors more inclined to say no. Two students, SLife and SPhil, felt that stricter selection standards ought to be applied to higher-priced books. Likewise, LLang and FFine mentioned that it might be appropriate to relax the usual selection standards for lower-priced books. As a group, the librarians were understanding of this approach ("when the book costs so little, it hardly matters"), although they did feel strongly that standards such as accuracy and absence of bias were nonnegotiable.

Publisher was mentioned eight times: once with regard to university press status ("not a university publisher") and seven times with regard to reputation or perceived quality (for instance, "publisher is not the greatest"). All the publisher-related comments were made by librarians, and university presses were not immune from criticism.

As shown under Other reasons, unclear or poorly written reviews were sometimes regarded as a sign that the book itself was not suitable for selection. This supports the idea mentioned earlier, that no is the default decision and that yes decisions are possible only when the selector feels that reliable information is available.

\section{Differences among Librarians, Faculty, and Students}

The previous section identified the book characteristics associated with positive or negative selection decisions, treating all the study participants as a single group. In contrast, this section investigates whether there are systematic differences in the books selected by librarians, faculty, and students. Although the absence of consensus provides a context for all these results, it is notable that the book selection decisions of the librarians (average phi $=0.26$ ) and the faculty $(0.26)$ were more closely related than those of the students $(0.15)$. That is, each student's selections were unlike those of the other students. The selection rates of the three groups were very similar, however, with just one meaningful distinction: faculty had a higher selection rate $(50 \%)$ than librarians $(43 \%)$ and students $(45 \%)$. 
Differences in the characteristics of selected books. As previously discussed, the first columns of table 2 show how various book characteristics are related to the overall selection rate. The table 2 results for librarians and faculty confirm that these same relationships hold true when each group is considered separately. As the table shows, however, students' selection decisions are more difficult to predict. In comparison with librarians and faculty, students are less likely to be influenced by the reviewer's rating, caveats in the review, readership category, university press status, and price. The difficulty of predicting or explaining students' choices can be seen in the low $B$ coefficients, the high standard errors, and the low $\mathrm{R}^{2}$ value for students.

Selectors' comments. Librarians are especially likely to have unfavorable attitudes toward multidisciplinary works that appear unfocused or poorly conceived. The negative aspects of multidisciplinarity were mentioned by five of the librarians (LLife, LSoc, LLang, LGen2, and LGen3) but by just one faculty member (FLang) and by no students. Reporting on The Language of Plants, an edited volume that covers aspects of biology, chemistry, communication, literature, and politics, LLang wrote "not sure who would benefit." 37 The book was selected by six faculty, three students, and two librarians. Likewise, China Lake: A Journey into the Contradicted Heart of a Global Climate Catastrophe combines engineering and climatology with "passages discussing shamanism, weather warfare, and personal reflections on [the author's] family." ${ }^{38}$ Six faculty selected the book, but only two librarians chose it. LLife and LGen3 each drew attention to CHOICE's description of the book as "a wandering narrative," and LGen3 referred to it as "pseudo-science."

Students' perspectives on the curriculum were sometimes more limited than those of the librarians and faculty. Andrew Wyeth: In Retrospect was not chosen by any of the seven students, who declared it "[not] necessary for any courses at Manhattan College" (SSoc2). ${ }^{39}$ The book was selected by four librarians and three faculty, however. Students had similar views about The Reception of Vatican II, which was chosen by five librarians and five faculty but by just one student. ${ }^{40}$ This suggests that MC students are not always aware of, or concerned with, the college's less prominent courses and programs.

\section{Differences among Subject Specialists}

While the results for librarians, faculty, and students are based on data for all 22 study participants, those for subject specialists in the natural sciences, the social sciences, and the humanities are based on data for just the eight faculty and the three librarians with substantial experience as subject selectors (LLife, LSoc, and LLang).

Differences in selection rates. As noted earlier, selection rates vary with the subject of the book, but they vary even more with the selector's subject area (see table 4). For example, faculty and librarians in the humanities selected far more books than those in the natural sciences ( $57 \%$ vs. $29 \%)$.

Table 4 also reveals that selectors in most fields-all but NAT - are especially likely to choose books in their own subject areas. Those in the SOC category selected social science, business, and education books at higher-than-average rates, while those in the HUM category selected language, philosophy, history, and fine arts books at higher-than-average rates. The same pattern can be seen in the individual data for seven of the eight SOC and HUM selectors.

The last two rows of table 4, Percent in own category and Benchmark percent provide further support for this finding. They deal not with the three broad subject areas (NAT, SOC, and HUM), but with the nine more specific categories: Phys, Life, Soc, Bus, Ed, Lang, Phil, Hist, 


\begin{tabular}{|l|c|c|c|c|c|}
\hline \multicolumn{5}{|c|}{$\begin{array}{c}\text { TABLE 4 } \\
\text { Average Percentage Selected in Each Book Subject Category, for All Selectors and Each of } \\
\text { Three Selector Groups }\end{array}$} \\
\hline & & \multicolumn{4}{c|}{ Average Percentage Selected } \\
\hline & $\begin{array}{c}\text { Number } \\
\text { of Books }\end{array}$ & All Selectors & NAT & SOC & HUM \\
\hline All subjects & 287 & 46 & 29 & 52 & 57 \\
\hline Phys & 28 & 47 & 27 & 51 & 59 \\
\hline Life & 33 & 42 & 30 & 54 & 53 \\
\hline Soc & 52 & 48 & 34 & 58 & 58 \\
\hline Bus & 5 & 46 & 33 & 53 & 52 \\
\hline Ed & 7 & 56 & 48 & 67 & 63 \\
\hline Lang & 25 & 48 & 25 & 53 & 66 \\
\hline Phil & 36 & 50 & 31 & 52 & 58 \\
\hline Hist & 58 & 50 & 33 & 55 & 65 \\
\hline Fine & 43 & 35 & 18 & 36 & 43 \\
\hline Percent in own category & - & 52 & 37 & 58 & 59 \\
\hline Benchmark percent & - & 47 & 44 & 51 & 46 \\
\hline
\end{tabular}

and Fine. For each selector group, Percent in own category is the percentage of the books in each specific subject category that were chosen by the selectors with a background in that same category; Benchmark percent is the percentage of the books in each subject category that were chosen by all the selectors. Table 4 shows that, with one exception, each of the Own category values is substantially higher than the corresponding Benchmark value. That is, selectors in every group but NAT are especially likely to choose books in their own subject areas. This strong pattern persists despite specific instructions that asked each selector to consider the needs of the college as a whole.

Natural science selectors are an exception to the general pattern, however. All three selectors in the NAT group - one librarian and two faculty - chose fewer natural-science books than the other selectors did. There are at least three plausible explanations for this. First, original scientific research is seldom reported in books. This may lead NAT selectors to underestimate the value of books that are intended for other purposes, such as instructional texts, guides, biographical narratives, and popular treatments. Second, natural science selectors may focus on the needs of science majors while SOC and HUM selectors more fully consider the needs of lower-division students learning about key scientific topics such as evolution and climate change. Finally, NAT selectors, unlike SOC and HUM selectors, may discount the value of books that combine elements of the natural and social sciences. As described later, the selectors' comments appear to support the second explanation and possibly the third. They do not address the first.

Differences in the characteristics of selected books. Table 5 presents descriptive data for the books chosen by NAT, SOC, and HUM selectors. ${ }^{41}$ As the table shows, the books chosen by SOC and HUM selectors are generally quite similar. Again, however, the NAT group is distinctive. Compared with the other selectors, those in the natural sciences are more likely to select books with low reviewer ratings, less likely to select books in readership category 
1 (lower-division), more likely to select books in category 3 (graduate/professional), less likely to select university press books, and more likely to select high-priced books. The results for readership category are consistent with the idea that natural scientists tend to focus on the needs of students majoring in the sciences.

Selectors' comments. The respondents' comments further support the assertion that NAT selectors emphasize the needs of science majors while SOC and HUM selectors are especially receptive to multidisciplinary works with a natural science component. Brain vs. Computer:

\begin{tabular}{|c|c|c|c|c|c|}
\hline Descriptive Data for All Books, Sele & $\begin{array}{r}\text { TABLE } 5 \\
\text { ted Books, ar }\end{array}$ & nd Books & Selected b & Each of Si & ix Groups \\
\hline & $\begin{array}{l}\text { Average for } \\
\text { All Books, } \\
\text { Selected } \\
\text { and } \\
\text { Nonselected }\end{array}$ & $\begin{array}{c}\text { Average } \\
\text { for All } \\
\text { Selected } \\
\text { Books }\end{array}$ & $\begin{array}{c}\text { Average } \\
\text { for Books } \\
\text { Selected } \\
\text { by NAT }\end{array}$ & $\begin{array}{c}\text { Average } \\
\text { for Books } \\
\text { Selected } \\
\text { by SOC }\end{array}$ & $\begin{array}{c}\text { Average } \\
\text { for Books } \\
\text { Selected } \\
\text { by HUM }\end{array}$ \\
\hline Average reviewer rating & 2.5 & 2.7 & 2.5 & 2.6 & 2.7 \\
\hline Percent with 4-star ratings (essential) & 8 & 13 & 8 & 13 & 15 \\
\hline $\begin{array}{l}\text { Percent with 3-star ratings (highly } \\
\text { recommended) }\end{array}$ & 34 & 43 & 34 & 42 & 46 \\
\hline $\begin{array}{l}\text { Percent with 2-star ratings } \\
\text { (recommended) }\end{array}$ & 55 & 43 & 55 & 43 & 39 \\
\hline Percent with 1-star ratings (optional) & 3 & 1 & 3 & 3 & 0 \\
\hline $\begin{array}{l}\text { Percent with 0-star ratings (not } \\
\text { recommended) }\end{array}$ & 0 & 0 & 0 & 0 & 0 \\
\hline Percent with caveats/reservations & 3 & 1 & 3 & 1 & 1 \\
\hline Average readership level & 1.7 & 1.5 & 1.7 & 1.5 & 1.5 \\
\hline $\begin{array}{l}\text { Percent in readership category } 1 \text { (lower- } \\
\text { div.) }\end{array}$ & 47 & 56 & 47 & 59 & 58 \\
\hline $\begin{array}{l}\text { Percent in readership category } 2 \text { (upper- } \\
\text { div.) }\end{array}$ & 35 & 34 & 35 & 29 & 33 \\
\hline $\begin{array}{l}\text { Percent in readership category } 3 \text { (grad./ } \\
\text { prof.) }\end{array}$ & 17 & 10 & 17 & 13 & 8 \\
\hline Percent from university presses & 65 & 69 & 65 & 67 & 68 \\
\hline Median price & 39.95 & 36.24 & 39.95 & 36.64 & 38.30 \\
\hline Average price & 54.38 & 49.10 & 54.38 & 49.66 & 50.32 \\
\hline Percent with high price & 30 & 22 & 30 & 21 & 24 \\
\hline Percent with low price & 27 & 31 & 27 & 27 & 30 \\
\hline Median pages & 280 & 285 & 280 & 295 & 285 \\
\hline Average pages & 304 & 312 & 304 & 320 & 315 \\
\hline Percent long books & 30 & 30 & 30 & 33 & 32 \\
\hline Percent short books & 30 & 27 & 30 & 27 & 26 \\
\hline
\end{tabular}


The Challenge of the Century was selected by none of the NAT selectors but by 67 percent of those in the social sciences and 80 percent of those in the humanities. ${ }^{42}$ FLang called it "wideranging and provocative," and FFine reported that it would be "helpful for [computer information systems] and other programs." Likewise, a book on mathematics and video games was selected by none of the NAT selectors but by all of the HUM selectors. ${ }^{43}$ Natural Defense: Enlisting Bugs and Germs to Protect Our Food and Health elicited unfavorable comments from the NAT selectors but favorable comments from the SOC selectors, all of whom chose it. ${ }^{44}$

\section{Characteristics of Effective and Ineffective Book Selectors}

The data compiled for this project allow us to evaluate selectors as well as books. In the absence of clear right or wrong selection decisions, we assume that effective selection represents the collective interests of the three main stakeholder groups: librarians, departmental faculty, and students. Within this framework, effective selectors are those whose decisions most closely match those of the other selectors. Specifically, each selector's effectiveness is the point-biserial correlation between his or her selection decisions (coded 1 for yes, 0 for no) and the overall selection rates for each of the 287 books. Three other methods of assessing selectors' effectiveness were considered, but all were found inadequate in one or more respects. ${ }^{45}$

Selectors' effectiveness. Based on the standard used here, librarians and faculty are equally good at making selection decisions. The average point-biserial correlation $\left(\mathrm{r}_{\mathrm{pb}}\right)$ value for librarians is 0.55; for faculty, 0.54. Students are less effective selectors, with an $r_{p b}$ value of 0.42 .

The top five selectors, in terms of overall effectiveness, include four faculty and one librarian with $\mathrm{r}_{\mathrm{pb}}$ values from 0.65 to 0.71 . The top 10 selectors include five faculty and five librarians with $\mathrm{r}_{\mathrm{pb}}$ values from 0.56 to 0.71 . In contrast, six of the seven students can be found among the 10 selectors whose decisions least closely match the overall selection pattern; those 10 selectors have $r_{p b}$ values ranging from 0.05 to 0.50 . Clearly, librarians and faculty outperform students in their ability to match the decisions of the group as a whole. There is no clear pattern with regard to subject specialization, however. No area of expertise can be linked to consistently better or worse performance as a book selector.

The overall effectiveness values represent all selection decisions. It is possible, however, that subject knowledge and disciplinary expertise make selectors more effective in their own subject areas than in others. To evaluate this possibility, we compared the individual selectors' decisions with the selection rates for books in their own subject areas. The results reveal that one faculty selector, FEd, was considerably better at matching the group's selections in her own subject area, with an overall $r_{\mathrm{pb}}$ value of 0.50 but a field-specific value (for education) of 0.98. Perhaps more notably, two faculty selectors-FFine and FPhys-were especially unlikely to match the group's decisions in their own subject areas. FFine had overall and field-specific $r_{\mathrm{pb}}$ values of 0.56 and 0.34 , respectively, while FPhys had values of 0.67 and 0.50 . This finding raises the possibility that the subject backgrounds of FFine and FPhys actually led them to make more informed but distinctive decisions in these areas, since expertise in fields such as art and mathematics is not shared among librarians and faculty to the same extent as expertise in fields such as history and sociology. It also illustrates a potential weakness of our approach, which counts effective selection as that which matches the preferences of multiple stakeholders rather than that which matches the preferences of subject experts. ${ }^{46}$ 
Characteristics that influence selectors' effectiveness. Just as OLS regression can be used to quantify the factors that influence book selection (see table 2), it can also be used to show the impact of selectors' characteristics on their ability to match the decisions of the group as a whole. The regression analysis presented in table 6 uses several individual characteristics to predict the overall effectiveness scores of the 22 selectors - the point-biserial correlations $\left(\mathrm{r}_{\mathrm{pb}}\right)$ between their individual selection rates and those of the group as a whole. The $\mathrm{R}^{2}$ value, 0.49 , reveals that the eight explanatory variables together account for roughly half the variation in selectors' effectiveness. Each $B$ coefficient shows the impact of the relevant characteristic on the selector's overall effectiveness score.

\begin{tabular}{|c|c|c|}
\hline Individual Characteristics That Influen & -OLS & n Results \\
\hline & B & SE \\
\hline Librarian & 0.16 & 0.10 \\
\hline Faculty & 0.37 & 0.10 \\
\hline Book selection experience as librarian & 0.45 & 0.33 \\
\hline Book selection experience as faculty & -0.06 & 0.10 \\
\hline Years at MC as librarian & 0.01 & 0.02 \\
\hline Years at MC as faculty & 0.01 & 0.01 \\
\hline Years of professional experience as librarian & -0.02 & 0.02 \\
\hline Years of professional experience as faculty & -0.02 & 0.01 \\
\hline Constant & 0.42 & 0.04 \\
\hline Adjusted $\mathrm{R}^{2}$ & 0.49 & \\
\hline SE of estimate & 0.12 & \\
\hline $\begin{array}{l}\text { The dependent variable, overall effectiveness, } \\
\text { selection rate and the individuals' selection c } \\
\text { Student is the reference category. } \\
B \text { and } S E \text { are not standardized. }\end{array}$ & betwe & \\
\hline
\end{tabular}

The explanatory variables include librarian status and faculty status (coded yes or no, 1 or 0 ) as well as book selection experience, years at Manhattan College, and professional experience. Book selection experience is coded 1 for those with significant book selection experience and 0 for all others. ${ }^{47}$ Librarians received credit for book selection experience if "regular (e.g., weekly or monthly) selection of books/monographs was a significant component of [their] professional work" for one or more years. Faculty received credit if they had at least a year's experience with "book selection for [their] academic department, either at Manhattan College or elsewhere" through the selection of books from sources such as CHOICE reviews, GOBI records, or publishers' catalogs. Professional experience, in years, was self-reported (librarians) or counted from the PhD date (faculty) while years at $M C$ was counted as the number of years since the respondent's first appointment at Manhattan College. ${ }^{48}$

The librarian and faculty coefficients in table 6 reveal that, among selectors with neither book selection experience nor professional experience, faculty have an advantage over librarians - and librarians an advantage over students - in their ability to match the selections of the group. (See the $B$ coefficients for librarian and faculty. Students are the reference category, with 
a $B$ value of zero.) One possible interpretation is that $\mathrm{PhD}$ study provides a better background for book selection than does professional education in library and information science. The experiences of doctoral students and faculty may help them cultivate a critical perspective that is useful in evaluating the methods, outcomes, and products of scholarly work.

Although experience as a book selector can dramatically improve librarians' performance, it brings no such advantage for faculty. This may reflect the nature of the book selection activities undertaken by each group. Librarians with selection experience are usually subject liaisons, and book selection is a significant component of their work. In contrast, the faculty selector role is usually more limited.

As noted earlier, book selection experience is represented here in binary form. Preliminary analyses revealed that the predictive power of the variable is strongest when it is expressed as a simple yes/no distinction (some book selection experience vs. none) rather than in years. This suggests that each year of selection experience does not improve performance by an equal, incremental amount. At the same time, a clear distinction can be drawn between librarians with and without book selection experience. Within this sample, the librarians with book selection experience have a minimum of nine years' experience. We can therefore conclude that, for librarians, the advantage of book selection experience accrues at some point before the ninth year.

Among both librarians and faculty, experience at Manhattan College has a modest but positive impact on effectiveness. This is not unexpected, since selectors with more years at MC may have better knowledge of the curriculum, the students, and the faculty, along with a heightened awareness of the distinction between "good books" and books that are especially appropriate for this particular setting.

Oddly, however, length of professional experience (as a librarian or faculty member, at MC or elsewhere) appears to be inversely associated with selectors' effectiveness. There are several possible explanations for this counterintuitive result. Graduate programs may help cultivate the skills needed for book selection more effectively now than in the past. Recently hired librarians and faculty may be better qualified for book selection (and for other professional tasks) due to greater competition in the job market-a stronger selection mechanism. Alternatively, experienced librarians and faculty may be less likely to evaluate new literature on a regular basis, since they rely more heavily on the knowledge they have developed over the years.

\section{Conclusion}

\section{Main Findings}

Although selectors are seldom in close agreement about particular titles, their decisions are strongly and consistently related to the ratings assigned by the CHOICE reviewers. Other factors that encourage a yes decision, in rough order of importance, are suitability for lowerdivision undergraduates, the absence of caveats in the review, reasonable price, and publication by a university press. When asked to comment on their reasons for selecting or not selecting particular titles, respondents mentioned 22 reasons in five broad categories: Scope of the collection, Intended audience, Quality of the book, Price, and Publisher. Their comments suggest that selectors are willing to relax certain selection criteria if others are exceeded, that selectors' generally favorable attitudes toward multidisciplinary works do not extend to all such books, and that titles in areas unfamiliar to the selector are less likely to be chosen. This last 
finding suggests a more general collection development principle - that the default decision is no, and that a yes decision requires that the selector make a case for the book by drawing on his or her own knowledge of the field. Within this framework, selectors can be expected to select fewer books in the areas they are less familiar with.

Our analysis confirms the fundamental importance of reviewers' ratings and comments, as noted in earlier work. ${ }^{49}$ The results presented here are not always consistent with previous research, however. While Zhang identified projected use as a major factor in e-book selection, ${ }^{50}$ relatively few of our respondents mentioned that criterion. Likewise, Shoki reported that publisher's reputation is of primary importance while readability (and, by extension, appropriateness for undergraduates) is not. ${ }^{51}$ Both those assertions are contrary to our results.

The books selected by librarians, faculty, and students are generally similar to those selected by the set of all 22 study participants. The book characteristics associated with yes decisions are also similar across all three groups. Nonetheless, it is clear that subject specialists (both librarians and faculty) are especially likely to say yes to books in their own subject areas. This is consistent with $\mathrm{Chu}^{\prime}$ 's observation that both groups tend to focus on the needs of their own departments and students. ${ }^{52}$ Natural scientists tend to select relatively few books, however, and they are especially unlikely to select books in the physical sciences.

Overall, librarians and faculty are equally effective as selectors. This is not unexpected, since they use similar criteria when selecting books ${ }^{53}$ and tend to select titles with equally high library circulation. ${ }^{54}$ As previous research suggests, ${ }^{55}$ however, undergraduate students are considerably less effective at matching the decisions of the group as a whole.

This raises a question: Are students' selections worse or simply different? That is, do students have their own implicit selection criteria that are distinct from those of librarians and faculty? Our data suggest that they do not. After all, students' decisions are only weakly correlated with each other (average phi $=0.15$ ); stronger correlations can be seen among both librarians (0.26) and faculty (0.26). Likewise, the correlation matrix of the selectors' decisions reveals no secondary or alternate pattern specific to students. Although some authors have argued that students' customer perspective gives them valuable insight into collection development issues, ${ }^{56}$ their short-term performance goals are not always aligned with the learning goals of the faculty or the university. ${ }^{57}$ Moreover, our results suggest that there is no "student perspective" common to undergraduates. If there are benefits to student input in selection decisions, they are grounded in the capabilities and characteristics of each individual student - not in a set of selection criteria that are common to student selectors.

Among individuals with no book selection experience, faculty are more effective selectors than librarians. However, book selection experience improves the effectiveness of librarian selectors considerably more than it improves the effectiveness of faculty selectors. As might be expected, length of experience at Manhattan College is modestly but directly associated with selection effectiveness. This last finding is consistent with qualitative research that suggests institutional tenure has only a minor impact on the effectiveness of faculty selectors. ${ }^{58}$

\section{Research and Practice}

This project is the first quantitative study of the book selection decisions made by librarians, faculty, and students under naturalistic conditions. It is based on data for a set of 287 CHOICE-reviewed books in subject areas common to many undergraduate colleges. Although 
our single-institution sample does not allow us to generalize beyond Manhattan College, this study sets forth a straightforward method for the conduct of similar research elsewhere.

Because the study is exploratory, it raises quite a few questions for further investigation. These can be grouped into four categories.

1. Representativeness and reliability. Further research may help establish whether the results reported here are applicable outside the MC setting. For instance, are these findings consistent across the various types of colleges and universities? Can the same reasons for selection or nonselection be identified elsewhere? Because selection decisions involve the interaction of three elements - the book itself, the selector, and the context (such as students, faculty, curriculum, resources, and institutional priorities) - a series of context-specific (institution-specific) studies would allow for the investigation of book-selector relationships without the confounding effects of differences in context. Further investigations might also consider whether selectors' decisions are reliable over time. Would these same selectors choose the same books three years later, assuming no significant changes in the curriculum?

2. The book selection process. Several respondents mentioned their willingness to relax the usual selection criteria when considering low-priced books. This suggests a more general question: When making their decisions, do selectors simply weight each relevant factor, explicitly or implicitly, and intuitively add up the weighted scores, or do some factors take priority over others (example: “This book is such an important contribution to the field that I'll relax our usual standards for intended audience and readership level")? Is there a hierarchy of factors based on the extent to which each can supersede or offset the others? Does price influence the selection decision in a linear fashion, or is there a threshold level at which high price becomes an issue? Finally, is there a reliable empirical basis for the "unsuccessfully multidisciplinary" status identified by the MC librarians?

3. Selectors' effectiveness. Our assessment of selectors' effectiveness is based on the assumption that effective selectors are those whose decisions most fully represent the interests of the major stakeholders. Do alternative definitions of effectiveness lead to different results? What specific elements of selection experience influence effectiveness? What makes some selectors especially effective or ineffective when choosing books within their own subject areas? Why are student selectors less likely to be influenced by the book characteristics shown in table 2? Are there other factors, not represented here, that guide their decisions? It would also be useful to investigate whether the faculty's selections (in relation to the librarians') are complementary or duplicative-whether it is cost-effective to routinely solicit selections from both groups - and whether collaborative decision-making that involves both librarians and faculty is an improvement over independent selection by either group. Likewise, further research might explore the common practice of assigning book selection duties to less experienced faculty, ${ }^{59}$ evaluating whether a reliance on more experienced faculty would lead to different selection decisions.

4. Selection tools. Given the importance of reviewers' ratings, the quality and consistency of selection tools is of paramount importance. Do the determinants of yes and no decisions change when selection tools other than CHOICE, such as GOBI, are used? Are the CHOICE ratings and readership categories reliable, or do they vary across 
reviewers? Are the readership categories consistent with readability scores? With the level of prior knowledge needed to understand the book's content? Likewise, do CHOICE ratings vary systematically by subject area? Is there rating inflation in certain disciplines, or among certain kinds of reviewers?

Although this project was designed to address particular research goals, our findings also suggest several recommendations for practice. First, our results demonstrate that subject selectors - both librarians and faculty - tend to favor books in their own subject areas. This is perhaps appropriate when each selector is responsible for only a limited range of subjects, but it also raises the possibility of bias when selectors adopt a generalist role or when they feel a stronger commitment to some of their assigned subjects than to others. Second, libraries developing book selection guidelines may want to emphasize the five main themes brought up by selectors in their comments: Scope of the collection, Intended audience, Quality of the book, Price, and Publisher. These five themes are more inclusive than those outlined in some previous studies. ${ }^{60}$ Third, Stieve and Schoen have demonstrated that students value books that allow them to readily identify and use the information most appropriate to their needs-books with straightforward organization and helpful indexing, for instance. ${ }^{61}$ Although our study did not address these book characteristics, our results do suggest that students consider factors other than those that drive the decisions of librarians and faculty. Librarians may want to more fully consider the student-centric selection criteria mentioned by Stieve and Schoen.

While all the selectors who participated in our study were familiar with the MC book selection guidelines, certain concepts-relevance to the curriculum, in particular-were sometimes interpreted in a variety of ways. Most selectors took a broad view of relevance, although others tried to match each title to a particular course or assignment. This suggests a need to discuss the book selection guidelines fully and widely, and with stakeholders other than the librarians. Finally, our results show that, for librarians, effectiveness in book selection is most closely tied to experience as a selector - not to overall professional experience. Training programs that incorporate intensive selection activities may or may not bring the same benefits as real-life selection experience.

Informal evidence suggests that our book selection exercise has itself been useful in the training of librarian selectors. The training program, which commenced in fall 2018, draws on our improved understanding of faculty and student perspectives, our continuing discussions of selection criteria and methods, and our newfound awareness of the extent to which each individual's decisions are consistent with those of the group. The project has made the selectors more familiar with the details of our book selection guidelines and more mindful of the issues that are likely to arise during the application of those guidelines. We anticipate that the library liaison program, guided by the results of this study, will also help increase the faculty's awareness of our book selection standards and methods. 


\section{APPENDIX. Book Selection Guidelines (Questions to Consider)}

\section{The Manhattan College (MC) Context}

\section{Is the book within our subject and language scope?}

- The books we select should support the MC majors and minors, the MC Core Competencies, or the work that students are likely to undertake in courses such as ENGL 110.

- Prefer books that correspond to undergraduate research paper topics.

- Books on "hot topics" (such as current social, political, and scientific issues) are often especially good candidates for selection, but be sure not to weaken our usual selection standards.

- Books that challenge common knowledge in a serious way may be especially useful, if they're based on evidence rather than speculation.

- Consider the number of students who are likely to benefit from the work. For instance, books on art, literature, or music will reach a broader audience of MC students if they deal with multidisciplinary themes such as the intersection of literature and politics.

- Acquire books in English only, except for primary historical works and books that support our foreign language programs.

Is it appropriate for MC students in terms of level and presentation style?

- Level refers to the reading ability, mathematical ability, research ability, and subject knowledge that students need in order to use the book effectively.

- Books intended primarily for upper-division students, graduate students, and faculty are often less useful than those that appeal to a broader range of readers.

- The readership guidelines in CHOICE are not always reliable. In at least some cases, highly specialized works carry a general readers designation.

- Consider not whether a typical MC undergraduate can make use of the book, but whether our best students can do so.

- Avoid books that are slanted toward audiences other than ours. We want human anatomy and pharmacology, for instance, but anatomy and pharmacology books intended specifically for medical students may not be appropriate for us.

Is it appropriate for MC students in terms of specificity/generality?

- Many books, including some excellent books, cover very specific topics that are unlikely to be chosen by MC students for their papers and assignments.

- Keep in mind that MC students nearly always prefer the "tried and true" - the Civil War rather than the War of 1812, Mexico rather than Uruguay, and autism rather than Landau-Kleffner Syndrome. We want Soviet Contributions to the Allied War Effort but probably not Belgian Contributions.

- Collect in greater depth within the more prominent MC major fields. Civil engineering, communications, education, finance, management, marketing, and mechanical engineering each have more than 150 majors. Art history, environmental science, environmental studies, French, peace studies, religious studies, Spanish, and urban studies each have 10 or fewer.

- Because CHOICE cards are circulated to the faculty in each academic department, we can often rely on those faculty to select more specialized research works (within the subject areas covered by CHOICE). 


\section{Is it of special interest to MC students and faculty?}

- Give special attention to books that support the scholarly work of a particular faculty member, to books written by people associated with the college, and to books of local interest (examples: Bronx, NYC, Lasallian Catholic community).

\section{What else do we have on the subject? What else is available on the subject?}

- In considering a new title, be aware of what we already own (subject, author, and date, for example) and of what else is available ("Wouldn't we want the other Hamilton biography instead of this one?").

- Consider uniqueness of presentation/approach as well as uniqueness of content, especially for introductory works.

\section{Characteristics of the Book Itself}

\section{Is it a good book?}

- Consider the book reviews available through CHOICE, GOBI, and other sources.

- The ratings provided by CHOICE - no stars (Not recommended), 1 star (Optional), 2 stars (Recommended), 3 stars (Highly recommended), and 4 stars (Essential) - may be helpful, but no book ought to be selected or excluded solely due to its rating.

- Consider the qualifications of the reviewer, and the possibility of bias in reviews-especially very negative ones.

- Consider the publisher's reputation. Know the top publishers and the marginal publishers within your subject areas. All else equal, prefer university presses.

- Keep in mind that some generally good publishers also publish low-quality books. This is especially relevant with regard to [nine particular publishers] and any publisher with a strong political bias.

- We do not normally acquire books from [three particular publishers].

- We do not acquire self-published books unless they have received very favorable reviews or are otherwise especially appropriate for our collection.

- Be wary when there's a mismatch between the claimed importance of the book and the publisher's reputation. Truly groundbreaking work is likely to be accepted by a top university press; a reputable but mid-level publisher is less likely to publish such work.

- If the author is not a scholar, check for signs that the research findings have been overstated, oversimplified, or misrepresented.

\section{Is the book coherent by subject and/or function?}

- Consider whether patrons will be able to find the book and assess its relevance using the discovery mechanisms (catalogs and bibliographic databases) available to them.

- For edited volumes, consider whether each individual chapter is discoverable. An important paper (chapter) in an edited volume is less likely to be found if the book (collection) itself is not coherent by subject.

- Select books that are coherent by subject (specific topic) and/or function (such as atlases, encyclopedias, handbooks, manuals, standards, statistical compendia, and test collections).

Is it current?

- Be aware that the length of time from manuscript submission to publication can vary substantially. 
- Consider the rate at which new knowledge is created within the field or subfield.

- Be wary of empirical studies that appear in book form within "journal disciplines."

- Consider whether the references are current.

- Consider whether the book is likely to be superseded by upcoming developments (such as political changes, changes in professional standards or legal requirements, methodological improvements, and new large-scale surveys or data sets).

\section{How much does it cost?}

- There are two key questions: "Can we afford the book?" and "Is it worth the price?" The books we select ought to satisfy both criteria.

- Know the average price of a book that meets our selection criteria within your assigned subject areas. Keep that price in mind as a benchmark, and consider whether a book that costs $50 \%$ more is $50 \%$ more useful.

- High price is often a sign that the publisher does not expect the book to sell well-that it's very specialized, and perhaps not appropriate for MC students.

- Consider relative price in terms of the other books (or other library resources) that might be purchased with the same amount of money. In purchasing a $\$ 140$ book, we are making a conscious decision not to purchase two $\$ 70$ books that might meet our students' needs in a more cost-effective manner.

- Consider the cost of maintaining and managing the content over time, especially with regard to the web and multimedia content that accompanies some books.

- Consider price within the context of sustainability. Whenever we purchase a book, we're sending a clear signal to the publisher that the price is not too high. By avoiding overpriced books, we help maintain the sustainability of the scholarly communication system.

\section{Special Considerations}

\section{Is the book an edited volume rather than a single-topic monograph?}

- In the natural and social sciences, be wary of authors' motives for publishing in edited volumes. Authors in these fields have a strong incentive to publish article-length papers in peer-reviewed journals rather than books. Journals tend to have a more systematic review process, and they are often more discoverable than individual book chapters.

- In at least some cases, book chapters are research papers that would not have survived the peer-review process. This is reflected in their citation impact. In sociology, for instance, a typical chapter in an edited volume is cited far less than a paper in a mid-range journal.

- Remember, however, that some collected works are especially useful to students. These include reference works, guidebooks, summary reviews of research fields or subfields, and other works that synthesize previous work rather than presenting original results.

\section{Does it consist entirely or chiefly of previously published material?}

- We do not normally acquire volumes that consist of previously published material except when they include additional content (such as synthesis) that substantially adds to the value of the book, or when the compilation process adds coherence that would otherwise be lacking - when the papers represent an important and emerging line of research that has only recently been recognized, for instance. 


\section{Is it a primary historical source, a textbook, an exhibition catalog, a music score, or a "con- sumable" item?}

- Primary historical sources are often especially valuable.

- We generally don't acquire textbooks or lab manuals other than those requested by faculty, except for textbooks that have received excellent reviews but are too expensive for use as required textbooks at MC; and textbooks in subject areas such as calculus and statistics, where a distinctly different perspective, approach, or method of presentation might reach students who aren't well served by the regular textbook.

- Choose art exhibition catalogs if they are of major artistic interest, special local interest, or strong thematic/multidisciplinary interest (example: "Explaining Evolution Through Art, 1850-1950"), or if they pertain to artists or works known to be covered in MC art courses.

- We don't normally acquire music scores except in response to patrons' requests. Likewise, we don't normally acquire workbooks, practice exams, or other "consumable" books.

\section{Notes}

1. Wenli Gao, Cherie Turner, and Irene Ke, "Programming Plus Subject Expertise: A Combined Approach for Approval Plan Modification," Collection Management 43, no. 2 (2018): 89-100; William H. Walters, "Evaluating Online Resources for College and University Libraries: Assessing Value and Cost Based on Academic Needs," Serials Review 42, no. 1 (2016): 10-17.

2. Since 2010, at least nine studies have compared the circulation of books acquired through title-by-title selection, approval plans, PDA programs linked to interlibrary loan requests, other PDA programs, e-book packages, donations, and other selection/acquisition methods. See, for example, Steven B. Carrico et al., "What Cost and Usage Data Reveals About E-Book Acquisitions: Ramifications for Collection Development," Library Resources \& Technical Services 59, no. 3 (2015): 102-11; Irene Ke, Wenli Gao, and Jackie Bronicki, “Does Title-ByTitle Selection Make a Difference? A Usage Analysis on Print Monograph Purchasing," Collection Management 42, no. 1 (2017), 34-47; Judith M. Nixon and E. Stewart Saunders, "A Study of Circulation Statistics of Books on Demand: A Decade of Patron-Driven Collection Development, Part 3," Collection Management 35, no. 3/4 (2010): 151-61; Rebecca Schroeder, "When Patrons Call the Shots: Patron-Driven Acquisition at Brigham Young University," Collection Building 31, no. 1 (2012): 11-14; David C. Tyler et al., "Patron-Driven Acquisition and Circulation at an Academic Library: Interaction Effects and Circulation Performance of Print Books Acquired via Librarians' Orders, Approval Plans, and Patrons' Interlibrary Loan Requests," Collection Management 38, no. 1 (2013): 3-32; David C. Tyler et al., "The Scholarly Impact of Books Acquired via Approval Plan Selection, Librarian Orders, and Patron-Driven Acquisitions as Measured by Citation Counts," College E Research Libraries 80, no. 4 (2019): 525-60; David C. Tyler et al., "Patron-Driven Acquisition and Monopolistic Use: Are Patrons at Academic Libraries Using Library Funds to Effectively Build Private Collections?" Library Philosophy and Practice (2014): paper 1149, available online at https://digitalcommons.unl.edu/libphilprac/1149/; David C. Tyler et al., "Just How Right Are the Customers? An Analysis of the Relative Performance of Patron-Initiated Interlibrary Loan Monograph Purchases," Collection Management 35, no. 3/4 (2010): 162-79; Jeffrey Waller, “Undergrads as Selectors: Assessing Patron-Driven Acquisition at a Liberal Arts College," Journal of Interlibrary Loan, Document Delivery \& Electronic Reserve 23, no. 3 (2013): 127-48.

3. CHOICE, a publishing unit of the American Library Association, provides monthly reviews of new books that are likely to be appropriate for undergraduate library collections. CHOICE is one of two major selection tools used by Manhattan College librarians and faculty to identify and evaluate new books for potential acquisition.

4. Mei Zhang, "Decision-Making in Libraries: E-Book Product Selection Practices in U.S. Academic Libraries," Proceedings of the Association for Information Science and Technology 54 (2017): 850-52.

5. Godwin Shoki, "Readability as Consideration for Book Selection Criterion in Book Selection Practices in Some Academic Libraries in Nigeria," presented at the 73rd IFLA General Conference and Council (2007), available online at http://origin-archive.ifla.org/IV/ifla73/papers/132-Shoki-en.pdf.

6. Dennis W. Dickinson, "A Rationalist's Critique of Book Selection for Academic Libraries," Journal of Academic Librarianship 7, no. 3 (1981): 138-43; Paul O. Jenkins, "Collection Development and Faculty," in FacultyLibrarian Relationships (Oxford, UK: Chandos, 2005): 37-54. 
7. Robert Neville, James Williams, and Caroline C. Hunt, "Faculty-Library Teamwork in Book Ordering," College \& Research Libraries 59, no. 6 (1998): 523-32.

8. Robert P. Haro, "Book Selection in Academic Libraries," College \& Research Libraries 28, no. 2 (1967): 104-06; Robert Sorgenfrei and Christopher Hooper-Lane, "Book Selection Responsibilities for the Reference Librarian: Professional Benefit or Burden?" Library Collections, Acquisitions, \& Technical Services 25, no. 2 (2001): 171-78.

9. Marybeth F. Grimes and Paul W. Grimes, "The Academic Librarian Labor Market and the Role of the Master of Library Science Degree: 1975 Through 2005," Journal of Academic Librarianship 34, no. 4 (2008): 332-39; Walters, "Evaluating Online Resources for College and University Libraries."

10. Mary Biggs, "Sources of Tension and Conflict Between Librarians and Faculty," Journal of Higher Education 52, no. 2 (1981): 182-201; Dickinson, "A Rationalist's Critique of Book Selection for Academic Libraries"; Jenkins, "Collection Development and Faculty"; Bruce Munro and Peter Philps, "A Collection of Importance: The Role of Selection in Academic Libraries," Australian Academic \& Research Libraries 39, no. 3 (2008): 149-70; Lan Shen, "Improving the Effectiveness of Librarian-Faculty Collaboration on Library Collection Development," Collaborative Librarianship 4, no. 1 (2012): 14-22.

11. William H. Walters, "Beyond Use Statistics: Recall, Precision, and Relevance in the Assessment and Management of Academic Libraries," Journal of Librarianship and Information Science 48, no. 4 (2016): 340-52; Walters, "Evaluating Online Resources for College and University Libraries."

12. Robbie B. Bingham, "Collection Development in University Libraries: An Investigation of the Relationship Between Categories of Selectors and Usage of Selected Items" (PhD diss., Rutgers University, 1979), 78-86; Tschera Harkness Connell, "Comparing the Circulation of Library Materials Ordered by Faculty and Librarians," Collection Management 14, no. 1/2 (1991), 73-84; G. Edward Evans, "Book Selection and Book Collection Usage in Academic Libraries," Library Quarterly 40, no. 3 (1970): 297-308; G. Edward Evans, "The Influence of Book Selection Agents upon Book Collection Usage in Academic Libraries" (PhD diss., University of Illinois, 1969), 69; John Eldon Geyer, "A Comparative Analysis of Book Selection Agents and Tools with Student Use at the Long Beach Community College Library" (EdD diss., University of Southern California, 1977), 47; Masanori Koizumi, abstract of "Book Selection by Librarians and Faculty Through Collective Evaluation Methods: A Case Study of Keio University Library in Japan," Library and Information Science 63 (2010): 41-59; S.J. Pritchard, "Purchase and Use of Monographs Originally Requested on Interlibrary Loan in a Medical School Library," Library Acquisitions: Practice \& Theory 4, no. 2 (1980): 135-39.

13. David L. Vidor and Elizabeth Futas, "Effective Collection Developers: Librarians or Faculty?" Library Resources \& Technical Services 32, no. 2 (1988): 127-36.

14. Vidor and Futas, "Effective Collection Developers."

15. Evans, "The Influence of Book Selection Agents upon Book Collection Usage in Academic Libraries."

16. Kristine J. Anderson et al., "Liberal Arts Books on Demand: A Decade of Patron-Driven Collection Development, Part 1," Collection Management 35, no. 3/4 (2010): 125-41.

17. Hui-Min Kuo, "Surveying Faculty Book Selection in a Comprehensive University Library," Collection Building 19, no. 1 (2000): 27-35.

18. Paul O. Jenkins, "Book Reviews and Faculty Book Selection," Collection Building 18, no. 1 (1999): 4-5.

19. Felix T. Chu, "Collaboration in a Loosely Coupled System: Librarian-Faculty Relations in Collection Development," Library \& Information Science Research 17, no. 2 (1995): 135-50; Felix T. Chu, "Librarian-Faculty Relations in Collection Development," Journal of Academic Librarianship 23, no. 1 (1997): 15-20.

20. Walters, "Beyond Use Statistics"; William H. Walters, "Expertise and Evidence in the Assessment of Library Service Quality," Performance Measurement and Metrics 4, no. 3 (2003): 98-102; William H. Walters, "Patron-Driven Acquisition and the Educational Mission of the Academic Library," Library Resources \& Technical Services 56, no. 3 (2012): 199-213.

21. Lisa Shen et al., "Head First into the Patron-Driven Acquisition Pool: A Comparison of Librarian Selections versus Patron Purchases," Journal of Electronic Resources Librarianship 23, no. 3 (2011): 203-18.

22. Waller, "Undergrads as Selectors."

23. Tyler et al., "The Scholarly Impact of Books."

24. Michelle Twait, "Undergraduate Students' Source Selection Criteria: A Qualitative Study," Journal of Academic Librarianship 31, no. 6 (2005): 567-73.

25. Thomas Stieve and David Schoen, “Undergraduate Students' Book Selection: A Study of Factors in the Decision-Making Process," Journal of Academic Librarianship 32, no. 6 (2006): 599-608.

26. Study participants and selectors are used interchangeably throughout the text.

27. American Library Association, "CHOICE Selection Policy" (2018), available online at www.ala.org/acrl/ choice/selectioncriteria; American Library Association, "Information for CHOICE Reviewers" (2018), available online at www.ala.org/acrl/choice/reviewers. 
28. We ignored the general readers designation, which some reviewers appear to assign arbitrarily, even to highly specialized works.

29. For the past several years, MC book selection has been undertaken by selected faculty (one or more from each academic department) and by one particular librarian, LSoc. In fall 2018, the librarians' book selection responsibilities were transferred to the liaison librarians-the seven librarians who participated in the study. Our results are unlikely to be biased by the selection methods and perspectives specific to Manhattan College simply because a strong culture of book selection was not in place at MC before the study was conducted.

30. The MC book selection guidelines (see appendix A) were developed by LSoc and refined through discussions with all the librarians and several faculty (not the study participants) several months before the project began. They reflect the standards and practices used informally at MC over the years as well as the selection criteria presented in the library literature, such as G. Edward Evans and Margaret Zarnosky Saponaro, "Selecting Materials," in Collection Management Basics, 6th edition (Santa Barbara, CA: Libraries Unlimited, 2012): 69-101; Peggy Johnson, "Developing Collections," in Fundamentals of Collection Development and Management, 3rd ed. (Chicago, IL: American Library Association, 2014): 135-91. The guidelines are not themselves innovative, except perhaps in their incorporation of coherence as a necessary attribute; see William H. Walters et al., "Guidelines for Collecting Aggregations of Web Resources," Information Technology and Libraries 17, no. 3 (1998): 157-60.

31. The 46 percent selection rate is slightly higher than the proportion of each month's CHOICE books that were ordered from CHOICE reviews during the previous five-month period (39\%). This is presumably because some CHOICE books are normally identified and chosen through other selection tools such as GOBI. Unfortunately, we do not have reliable selection rate data for the months prior to the study.

32. Throughout the text and tables, correlation refers to Pearson's $r$ for interval variables, Spearman's rho for ordinal variables, phi for binary variables, and point-biserial correlation for the comparison of interval and binary variables; see Peter Y. Chen and Paula M. Popovich, Correlation: Parametric and Nonparametric Measures, Quantitative Applications in the Social Sciences no. 139 (Thousand Oaks, CA: SAGE, 2002); David C. Howell, Statistical Methods for Psychology (Belmont, CA: Wadsworth, 2013), 305-13; Laerd Statistics, "Point-biserial Correlation Using SPSS Statistics" (2013), available online at https://statistics.laerd.com/spss-tutorials/point-biserialcorrelation-using-spss-statistics.php; Jason T. Newsom, "Point-biserial Correlation, Phi, \& Cramer's V" (2000), available online at http://web.pdx.edu/ newsomj/pa551/lectur15.htm.

33. Cemil Aydin, The Idea of the Muslim World: A Global Intellectual History (Cambridge, MA: Harvard University Press, 2017); Jenna Weissman Joselit, Set in Stone: America's Embrace of the Ten Commandments (New York, NY: Oxford University Press, 2017).

34. An alternative procedure is to treat each selection decision (each book/selector combination) as a separate case, using logistic regression with a binary dependent variable ( 1 or 0 , selected or not); see Scott Menard, Applied Logistic Regression Analysis, Quantitative Applications in the Social Sciences no. 106 (Thousand Oaks, CA: SAGE, 2002); Fred C. Pampel, Logistic Regression: A Primer, Quantitative Applications in the Social Sciences no. 132 (Thousand Oaks, CA: SAGE, 2000). Logistic regression produced substantive results nearly identical to those shown in table 2.

35. Kathryn H. Anthony, Defined by Design: The Surprising Power of Hidden Gender, Age, and Body Bias in Everyday Products and Places (Amherst, NY: Prometheus Books, 2017); Nicole Nguyen, A Curriculum of Fear: Homeland Security in U.S. Public Schools (Minneapolis: University of Minnesota Press, 2017).

36. Monica Gagliano, John Ryan, and Patricia Vieira, eds., The Language of Plants: Science, Philosophy, Literature (Minneapolis: University of Minnesota Press, 2017).

37. Gagliano et al., The Language of Plants.

38. Barret Baumgart, China Lake: A Journey into the Contradicted Heart of a Global Climate Catastrophe (Iowa City: University of Iowa Press, 2017); American Library Association, CHOICE review of China Lake, 2017.

39. Patricia Junker and Audrey Lewis, Andrew Wyeth: In Retrospect (New Haven, CT: Yale University Press, 2017).

40. The Reception of Vatican II, eds. Matthew L. Lamb and Matthew Levering (New York, NY: Oxford University Press, 2017).

41. The average for all selected books was obtained by calculating averages for the books selected by each of the 22 selectors, then averaging the selectors' values. The same procedure was undertaken for each of the six selector groups.

42. J.P. Fillard, Brain vs. Computer: The Challenge of the Century (Hackensack, NJ: World Scientific, 2017).

43. Matthew Lane, Power-Up: Unlocking the Hidden Mathematics in Video Games (Princeton, NJ: Princeton University Press, 2017).

44. Emily Monosson, Natural Defense: Enlisting Bugs and Germs to Protect Our Food and Health (Washington, DC: Island Press, 2017). 
45. One alternate method is to rely on library circulation data, comparing use statistics for the books selected by each study participant. That method requires that the library purchase all the CHOICE books, however, and it is not likely to generate meaningful circulation data for several years. It also relies on the assumption that circulation is a good indicator of scholarly or educational value, an assumption that has been challenged on several counts; see E. Stewart Saunders, "The Effect of Quality on Circulation in an Aging Collection," Collection Management 20, no. 3/4 (1996): 149-56; John P. Schmitt and E. Stewart Saunders, "An Assessment of Choice as a Tool for Selection," College \& Research Libraries 44, no. 5 (1983): 375-80; Walters, "Beyond Use Statistics"; Karen Carter Williams and Rickey Best, "E-Book Usage and the Choice Outstanding Academic Book List: Is There a Correlation?" Journal of Academic Librarianship 32, no. 5 (2006): 474-78. A second evaluation method is to regard book selection experience as a proxy for effectiveness, developing a single set of expert decisions based on the choices made by the three librarians with the most selection experience in each subject area. Unfortunately, any method based on the decisions of just three librarians is likely to be influenced by individual idiosyncrasies and biases. A third possibility is to rely on national or international library acquisitions (sales) as an indicator of effectiveness, asking selectors to evaluate the books published several years ago. Library acquisitions reflect the needs and preferences of institutions with priorities far different from those of Manhattan College, however, and decisions about the books published several years ago might be biased by information that has become available to the selectors only in the intervening years.

46. The differences between the overall results and the subject-specific results also suggest that secondary or alternative selection profiles might exist-that students, for instance, may have a legitimate and well-defined set of selection preferences that are systematically different from those of librarians and faculty. Our inspection of the actual selection decisions as well as the correlations among the decisions did not reveal the existence of subgroups or secondary patterns, however. There is no apparent pattern of selections unique to librarians, faculty, students, or any group of subject specialists.

47. Regression models with separate book selection experience variables for librarians and faculty were more predictive than those that used a single variable to represent book selection experience for both groups. Likewise, regression models with binary variables for book selection experience were more predictive than those that expressed experience in years. LLife, LSoc, FLife, FLang, FPhil each have at least 20 years of book selection experience; LLang, FEd, FHist, and FFine each have from 6 to 11 years of experience. The other selectors have no systematic book selection experience.

48. The 15 librarians and faculty selectors have from 1 to 48 years of professional experience (mean $=18.5$, $\mathrm{SD}=12.0)$ and from 1 to 43 years of experience at Manhattan College (mean = 14.5, SD = 12.9).

49. Tom M.Y. Lin, Yun Kuei Huang, and Wen I. Yang, "An Experimental Design Approach to Investigating the Relationship Between Internet Book Reviews and Purchase Intention," Library \& Information Science Research 29, no. 3 (2007): 397-415; Tom M.Y. Lin, Pin Luarn, and Yun Kuei Huang, "Effect of Internet Book Reviews on Purchase Intention: A Focus Group Study," Journal of Academic Librarianship 31, no. 5 (2005): 461-468.

50. Zhang, "Decision-Making in Libraries."

51. Shoki, "Readability as Consideration for Book Selection Criterion in Book Selection Practices in Some Academic Libraries in Nigeria."

52. Chu, "Collaboration in a Loosely Coupled System"; Chu, "Librarian-Faculty Relations in Collection Development."

53. Anderson et al., "Liberal Arts Books on Demand."

54. Bingham, "Collection Development in University Libraries"; Connell, "Comparing the Circulation of Library Materials Ordered by Faculty and Librarians"; Evans, "Book Selection and Book Collection Usage in Academic Libraries"; Evans, "The Influence of Book Selection Agents upon Book Collection Usage in Academic Libraries"; Geyer, "A Comparative Analysis of Book Selection Agents and Tools"; Koizumi, abstract of "Book Selection by Librarians and Faculty Through Collective Evaluation Methods"; Pritchard, "Purchase and Use of Monographs Originally Requested on Interlibrary Loan in a Medical School Library"; Vidor and Futas, "Effective Collection Developers."

55. Shen et al., "Head First into the Patron-Driven Acquisition Pool”; Waller, "Undergrads as Selectors"; Walters, "Beyond Use Statistics"; Walters, "Expertise and Evidence in the Assessment of Library Service Quality"; Walters, "Patron-Driven Acquisition and the Educational Mission of the Academic Library."

56. Karen A. Reiman-Sendi, Christopher A. Barnes, and Pamela J. MacKintosh, "Leveraging Student Employee Expertise for Collection Projects," Collection Management 43, no. 3 (2018): 198-208.

57. Walters, "Beyond Use Statistics," "Expertise and Evidence in the Assessment of Library Service Quality."

58. Felix T. Chu, "Collaboration in a Loosely Coupled System"; Chu, "Librarian-Faculty Relations in Collection Development."

59. Kuo, "Surveying Faculty Book Selection in a Comprehensive University Library." 
60. Evans, "The Influence of Book Selection Agents upon Book Collection Usage in Academic Libraries"; Kuo, "Surveying Faculty Book Selection in a Comprehensive University Library"; Shoki, "Readability as Consideration for Book Selection Criterion in Book Selection Practices in Some Academic Libraries in Nigeria"; Zhang, "Decision-Making in Libraries."

61. Stieve and Schoen, “Undergraduate Students' Book Selection." 